\title{
Corpos, emoç̃ões e risco como objetos sociológicos
}

\author{
Jalcione Almeida*
}

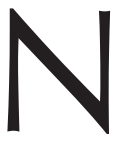

este número, Sociologias traz aos leitores a temática "corpos, emoções e risco". Nele os autores pretendem contribuir para uma reflexão sobre esses "objetos" no campo da sociologia, particularmente. No que concerne à temática em foco, se a noção-conceito-categoria risco não é nova na revista (ver, p. ex., Bosco; Ferreira, 2016; Mendes, 2016; Borraz, 2014; Brito; Barp, 2008), já "corpos" e "emoções" são objetos tratados aqui pela primeira vez. Como afirmam Alexandre Zarias e David Le Breton, organizadores deste dossiê, no conjunto de possibilidades investigativas a respeito do corpo, este é compreendido como um espelho do social (Le Breton, 1992; 1998; 2000), refletindo os aspectos afetivos da vida, dentro de um variado conjunto de emoções humanas.

*Universidade Federal do Rio Grande do Sul (UFRGS), Porto Alegre, Brasil. 
O corpo como objeto de investigação sociológica surge no século XIX, quando começa a se constituir como área/ temática de estudo tendo como referência os trabalhos de seus fundadores, entre os quais Émile Durkheim, Marcel Mauss e George Simmel. ${ }^{1}$ Gradativamente essa área vem se institucionalizando, crescendo muito nos últimos decênios, como se pode constatar na expressão acadêmica de periódicos e eventos científicos. ${ }^{2}$ No âmbito da International Sociological Association (ISA) se destacam um comitê de pesquisa, criado em 2008, e um grupo temático, constituído em 2016. No ano de 2019, no congresso da Associação Latino-americana de Sociologia (Alas), o grupo de trabalho Sociologia de los cuerpos y las emociones, criado em 2007, se fez presente.

Como confere Ferreira (2013), essa trajetória de estudos incitou um percurso conceitual que, do ponto de vista sociológico, levou à desnaturalização do corpo e à sua autonomização como objeto de estudo e área disciplinar específica no âmbito da sociologia, passando a assumir um reconhecido lugar acadêmico na contemporaneidade. Resgatado como potencial objeto de estudo em outras áreas acadêmicas, o corpo foi gradativamente se liberando de supostas determinações biológicas, ao mesmo tempo em que se desfigurava em suas múltiplas configurações teóricas, assumindo uma presença "quase obsessiva" (Cruz, 2000) na cultura contemporânea.

\footnotetext{
1Segundo Berthelot (1983), sempre houve uma sociologia implícita do corpo dentro das ciências sociais.

${ }^{2}$ Para uma verificação da discussão sobre corpo e emoções até o final do século passado, ver, para a produção acadêmica brasileira, entre outros, Sant'Anna (2000) e Koury (2014). Em âmbito internacional, entre outros, ver Le Breton $(1992 ;$ 1998; 2000) e Hochschild (1983). Nessas obras são retraçados alguns momentos característicos das sucessivas descobertas do corpo e das emoções nas últimas décadas do século XX, privilegiando autores e tendências socioculturais capazes de explicitar as principais características e paradoxos do interesse por esses "objetos" de estudo. Para a discussão de corpo articulado a risco, ver Le Breton (2009).
} 
Do ponto de vista sociológico, os organizadores deste dossiê - e os articulistas que o integram - tratam o corpo como signo das relações sociais, que encerra um conjunto de representações da vida individual e coletiva, compondo uma gramática que se tornou objeto particular de uma sociologia especializada, constituída contemporaneamente, e que já consolidou diferentes frentes de pesquisa. Boltanski (1971) compara a sociologia do corpo a um verdadeiro "colóquio interdisciplinar", integrado por especialistas de diversas áreas, que encontram pontos comuns em torno do tema sem chegar a formular o corpo mais precisamente como um objeto de investigação: uma sociologia do corpo hesitaria "entre uma análise econométrica que tenderia a dissolver o objeto de estudo na macroeconomia e uma análise micro tecnológica que tenderia a dissolvê-lo na anatomia ou na biologia, sem encontrar o tipo de abordagem que permitisse destacar sua dimensão propriamente social" (Boltanski, 2004, p. 104 apud Zarias e Le Breton, neste dossiê). Para Le Breton (1992, p. 3), "a sociologia do corpo constitui um capítulo da sociologia especialmente dedicado à compreensão da corporeidade humana como fenômeno social e cultural, motivo simbólico, objeto de representações e imaginários".

Já as emoções não estão separadas de seu suporte, de seu veículo expressivo, o corpo. Os organizadores deste dossiê afirmam que, no campo sociológico, assim como na antropologia, consequência da observação e da análise das relações sociais, as emoções também não podem ser tratadas como substância, entidade que antecipe ou contradiga as ações humanas; elas constituiriam uma dimensão da vida afetiva 
que se modifica constantemente por conta da infinidade de possibilidades de interação humana ${ }^{3}$.

Nos interstícios dos corpos e das emoções, a noçãoconceito-categoria de risco, segundo Le Breton (2009), revelaria as incertezas da existência individual que sempre oscilam entre a vulnerabilidade e a segurança, o impulso e a sensatez. O risco então assumiria diferentes sentidos: aquele ao qual estamos sujeitos - o que, de maneira geral, remete à noção de vulnerabilidade - e, também, o risco provocado, aquele associado às condutas que, de certa forma, nos colocam em perigo, seja de modo físico, social ou psicológico.

Nessa perspectiva, os cinco artigos que compõem este dossiê trazem um conjunto de reflexões e de referências teóricas que, segundo os organizadores, atualizam o debate em torno do corpo, das emoções e do risco. Esperamos que essas contribuições possam despertar interesses variados no campo sociológico e nas ciências sociais, a exemplo do que também ocorre frequentemente em outras áreas científico-acadêmicas.

Na seção Artigos este número de Sociologias traz ainda mais publicações. O primeiro trabalho intitula-se "Los Estados en los márgenes: soberanía y gubernamentalidad en el principal valle cocalero peruano", de autoria de Sofia Isabel Vizcarra Castillo e Christoph Heuser. Nele os autores tratam da governança em zonas com presença de "economias ilegais". A partir de um estudo qualitativo de caso, examinam a interação entre a intervenção estatal no vale dos rios Apurimac, Ene e Mantaro (VRAEM), no Perú, e seu objeto de governo. Esta

\footnotetext{
${ }^{3} \mathrm{Na}$ sociologia, os estudos sobre emoções passam a integrar uma subárea nos anos de 1990, como resultado de um processo iniciado nos EUA quase duas décadas antes e a partir de duas escolas sociológicas distintas, a funcionalista e a interacionista simbólica (cf. Marieze Rosa Torres, O que é sociologia das emoções? Disponível em: https://sociologiadasemocoes.blogspot.com/p/ filmes.html. Acesso em: 31 out. 2019).
} 
zona é a principal bacia cocalera peruana, com a presença de remanescentes do terrorismo e constitui uma das principais preocupações do governo. Governar o VRAEM tem sido um desafio que nem sempre obtém resultados, segundo os próprios planos do governo. Baseado em conceitos foucaultianos, este trabalho mostra que os habitantes do VRAEM são governados por pelo menos dois tipos de poderes de Estado: um poder soberano e um poder governamental. A convivência entre esses tipos de poderes permite explorar a multiplicidade de práticas governamentais existentes na zona, assim como as resistências locais a ambos tipos de poder.

A seguir, Amarildo Malvezzi, no artigo "Estética, liberdade e reflexividade: repensando Bourdieu", em resposta à acusação de que a sociologia de Pierre Bourdieu seja determinista e reprodutivista, principalmente devido ao modo pelo qual o conceito de habitus foi teorizado, busca resgatar "resíduos e margens de liberdade" nas obras do autor. Nesse contexto, a reflexividade aparece como princípio básico para uma leitura não determinista nem reprodutivista do pensamento bourdieusiano. Além das três possibilidades teóricas referidas por Bourdieu - a reflexividade sociológica, o conceito de hysteresis e a existência de habitus clivados - e de suas limitações, o presente artigo aponta para outra possibilidade ainda pouco explorada: a dimensão estética. Nesta, duas vias então se apresentam de fundamental importância: (i) o ofício do artista; e (ii) a experiência estética. A partir de ambas, o autor busca pensar a relação entre habitus, estética, liberdade e reflexividade.

Caio Vasconcellos, em "De Adorno a Marx: política e fetichismo", compara aspectos das interpretações de Karl Marx em 18 Brumário de Luís Bonaparte e no ensaio Teoria freudiana e o padrão da propaganda fascista, de Theodor Adorno, a respeito do caráter fetichista incorporado nas instituições e fenômenos 
políticos no mundo burguês - tanto em sua aurora, quanto em seu desenlace tardio. Em ambas as interpretações há uma curiosa reincidência de personagens e certos procedimentos que estimulariam o povo a agir como massa. Se é possível sublinhar, nas análises de Marx sobre a ascensão de Luís Bonaparte, consequências para a centralização e racionalização do aparato estatal, ressalta-se, por outro lado, o aspecto mitológico e fantasmagórico que organizaria o interior da esfera política. Segundo o autor, ao perscrutar o fenômeno do nazifascismo e do antissemitismo moderno, Adorno desenvolve uma interpretação a respeito das bases objetivas e dos mecanismos subjetivos envolvidos na dinâmica da relação entre o líder fascista e a massa de seus seguidores, também aqui se verificando a atuação de fenômenos fetichizados.

"Aníbal Quijano em seu labirinto: metamorfoses teóricas e utopias políticas" é o artigo de Deni Alfaro Rubbo. Nele o autor discute alguns desdobramentos presentes na trajetória intelectual e política de Aníbal Quijano (1930-2018). Procura-se reconstruir especialmente o contexto de "crise dos paradigmas" das ciências sociais e de declínio da esquerda marxista, que se manifestaram de modo acentuado na década de 1980, examinando como o sociólogo peruano encontrou soluções para a encruzilhada histórica que se anunciava a uma geração de cientistas sociais engajados na América Latina. O autor deste artigo parte da hipótese de que a cristalização de um ciclo de derrotas políticas possibilitou um novo redirecionamento teórico para Quijano entender a história latino-americana em sua moldura política e epistêmica. Por fim, é analisado o movimento de aproximação e distanciamento que Quijano faz com a tradição marxista a partir da perspectiva adotada da "colonialidade do poder".

O quinto e último artigo desta seção é de Veronica GómezUrrutia, Paulina Royo-Urrizola, Andrés Jiménez-Figueroa e Miguel 
Ángel Cruz-Cubillos, intitulado "Trabajo y familia: expectativas en jóvenes chilenos". Nele os autores partem do pressuposto de que os jovens enfrentam um mundo no qual o contrato social estabelecido no século passado, entre organizações e trabalhadores e entre os sexos, está mudando. O artigo explora então as expectativas dos jovens chilenos em relação ao trabalho e à família, em um contexto de crescente diversificação das biografias juvenis. Metodologicamente, o estudo se baseia em uma pesquisa realizada em 2017 com jovens do ensino superior ( $N=1358$ ) do centro-sul do Chile. Os resultados sugerem que, embora frequentemente sejam classificados como irresponsáveis ou como vítimas, esses jovens reivindicam a possibilidade de realização de projetos vitais próprios, mesmo com o contexto de desigualdade de gênero e limitações de acesso ao mercado de trabalho.

Por fim, na seção Resenhas, Sociologias apresenta o texto de Miqueli Michetti, "Périplos norte-atlânticos da sociologia contemporânea: a sociologia pragmática". Nele é resenhado o livro de Cyril Lemieux, La sociologie pragmatique (La Découverte, 2018), no qual o autor delineia a ascendência e a filiação dessa nova corrente disciplinar e explicita os princípios, conceitos e métodos que a caracterizam. Além disso, o sociólogo francês discorre sobre os principais "campos de pesquisa" trabalhados nesta abordagem e toma parte nos debates centrais que a têm atravessado, interna e externamente, nas últimas décadas. Ao fazer essa apresentação, a resenha busca ancorar a obra e a vertente preconizada em seu contexto de emergência e publicização, atentando às disputas posicionais que as enformam.

Desejamos a todos os nossos leitores uma boa leitura.

O Editor 


\section{Referências}

1. BERTHELOT, Jean-Michel. Corps et société. Cahiers Internationaux de Sociologie, v. LXXIV, 1983.

2. BOLTANSKI, Luc. Les usages sociaux du corps. Annales. Économies, Sociétés, Civilisations, v. 26, n. 1, p. 205-233, 1971.

3. BORRAZ, Olivier. O surgimento das questões de risco. Sociologias, v. 16, n. 35, p. 106-137, 2014.

4. BOSCO, Estevão; FERREIRA, Leila. Sociedade mundial de risco: teoria, críticas e desafios. Sociologias, v. 18, n. 42, p. 232-264, 2016. https://doi. org/10.1590/15174522-018004211

5. BRITO, Daniel C.; BARP, Wilson J. Ambivalência e medo: faces dos riscos na modernidade. Sociologias, v. 10, n. 20, p. 20-47, 2008.

6. CRUZ, Maria Teresa. A histeria do corpo. Revista de Comunicação e Linguagens, n. 28, p. 363-375, 2000.

7. FERREIRA, Vítor S. Resgates sociológicos do corpo: esboço de um percurso conceptual. Análise Social, v. 208, n. 48, p. 494-528, 2013.

8. HOCHSCHILD, Arlie R. The managed heart: commercialization of human feeling. Berkeley: University of California Press, 1983.

9. KOURY, Mauro G. P. Pela consolidação da sociologia e da antropologia das emoções no Brasil. Sociedade \& Estado, v. 29, n. 3, p. 841-866, 2014.

10. LE BRETON, David. La sociologie du corps. Paris: PUF, 1992.

11. LE BRETON, David. L'adieu au corps. Paris: Métailié, 1998.

12. LE BRETON, David. Passions du risque. Paris: Métailié, 2000.

13. LE BRETON, David. Condutas de risco: dos jogos de morte ao jogo de viver. Campinas: Autores Associados, 2009.

14. MENDES, José M. A dignidade das pertenças e os limites do neo-liberalismo: cidadania, catástrofes e Estado. Sociologias, v. 18, n. 43, p. 58-86, 2016. https:// doi.org/10.1590/15174522-018004303

15. SANT'ANNA, Denise B. de. As infinitas descobertas do corpo. Cadernos Pagu, n.14, p. 235-249, 2000.

16. ZARIAS, Alexandre; LE BRETON, David. Corpos, emoções e risco: vias de compreensão dos modos de ação individual e coletivo. Sociologias, v. 21, n. 52, p. , 2019. 
